\title{
Correction to: Nutrition and Periodontal Health in the Patients with Diabetes Mellitus: a Review from the Viewpoint of Endothelial Function
}

\author{
Atsushi Ishikado $^{1,2} \cdot$ Keiko Kondo $^{3} \cdot$ Hiroshi Maegawa ${ }^{1} \cdot K^{\prime}$ atsutaro Morino ${ }^{1,4}$ (i)
}

Published online: 8 December 2021

(c) Springer Nature Switzerland AG 2021

\section{Correction to: Current Oral Health Reports}

https://doi.org/10.1007/s40496-021-00297-3

The original article unfortunately was published with errors. Reference citations 10-20 were rearranged without any corrections from the author and "(under revision)" should be deleted.

The original article has been corrected.

Publisher's Note Springer Nature remains neutral with regard to jurisdictional claims in published maps and institutional affiliations.

The original article can be found online at https://doi.org/10.1007/ s40496-021-00297-3

Katsutaro Morino morino@belle.shiga-med.ac.jp

1 Department of Medicine, Shiga University of Medical Science, Seta, Tsukinowa, Otsu, Shiga 520-2192, Japan

2 Sunstar Inc, 3-1 Asahi-machi, Takatsuki, R\&D DepartmentOsaka 569-1195, Japan

3 Department of Public Health, Shiga University of Medical Science, Seta, Tsukinowa, Otsu, Shiga 520-2192, Japan

4 Institutional Research Office, Shiga University of Medical Science, Seta, Tsukinowa, Otsu, Shiga 520-2192, Japan 